Culture et histoire dans l'espace roman

Generación Romero Esteo

\title{
Invitados de honor
}

Javier Berger

\section{(2) OpenEdition}

\section{Journals}

Edición electrónica

URL: https://journals.openedition.org/cher/1138

DOI: 10.4000/cher.1138

ISSN: 2803-5992

\section{Editor}

Presses universitaires de Strasbourg

\section{Edición impresa}

Fecha de publicación: 11 julio 2019

Paginación: 169-172

ISBN: 979-10-344-0046-1

ISSN: 1968-035X

\section{Referencia electrónica}

Javier Berger, «Invitados de honor», reCHERches [En línea], 22 | 2019, Publicado el 05 octubre 2021, consultado el 17 noviembre 2021. URL: http://journals.openedition.org/cher/1138 ; DOI: https:// doi.org/10.4000/cher. 1138 


\title{
Invitados de honor
}

\author{
JAVIER BERGER
}

Lectura dramatizada en el Salón del Libro Teatral 2018, Madrid. Dirigida por Gabriel Fuentes, con Emilio Gutiérrez Caba y Fernando Cayo.

\author{
Personajes \\ Trinker.- Carablanca (60) \\ Hunger. - Augusto (40)
}

\section{Acto único}

Berlín 1933. Aplausos apagados. Bambalinas de un pequeño circo. El suelo salpicado de serrín, paja y algunas cagadas de animales. El carablanca TRINKER y el augusto HuNGER, con restos de merengue en sus caras, entran por el telón de salida. Hunger lleva un bate béisbol, detrás Trinker muy enfadado.

Hunger.- He dicho mi línea y después te he dado con el bate de béisbol en la cara. ¿Qué más dará el orden?

Trinker.- ¿Cómo? Primero me das con el bate, yo te pregunto “¿a qué viene eso?” y tú respondes: "se acabaron las tartas".

Hunger.- Es lo mismo.

Trinker.- No. Te lo he explicado mil veces: Uno, dos y tres. No puedes irte al tres directo, no hay sorpresa.

Hunger.- Eres un coñazo. Si no fuera por mí...

Trinker.- ¿Cómo?

HUNGER.- Vienen a verme a mí, no a un carablanca amargado y medio muerto.

Trinker.- ¡Fortaleza, templanza y prudencia! Las virtudes del artista de circo.

Hunger.- No debiste salir del seminario.

Música oriental que llega de la pista. Hunger y Trinker van preparándose para el siguiente número.

Trinker.- ¿Cuándo vamos nosotros? 
Hunger.- Después de tus amigos los elefantes bailarines.

Trinker.- Oh, no.

Hunger.- Seguro que te recuerdan, son tan rencorosos...

Barritos de elefantes mezclados con una fanfarria militar.

Trinker.- No soporto ir después de los elefantes.

Hunger.- Recuerda no tocarles la trompa.

Trinker.- Es ese olor que dejan en la pista.

Hunger.- Olor a elefante.

Trinker.- No, a mierda de herbívoro.

Hunger.- Como tú.

Trinker.- Herbívoro no, vegetariano. Además, tú tampoco comes carne.

Hunger.- Por falta de carne, no de ganas.

Aplausos. Trinker va vistiéndose de bailarina; Hunger de director de orquesta. Trinker.- Deberíamos separarnos.

Hunger. - ¿A qué viene eso?

Trinker.- Seguir cada uno por su lado.

Hunger. - ¿Me dejas?

Trinker.- Hoy es la última.

Hunger.- ¿Qué?

Trinker le entrega un telegrama a Hunger.

Trinker.- Lee el telegrama.

Hunger.- No llevo las gafas de cerca... Ni las de lejos... Ni las de leer alemán.

Trinker.- - Dame. (Lee) "Die Darstellung hat unserem Führer sehr gefallen. Er freut

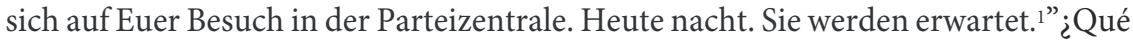
me dices?

Hunger.- ¿Qué? Que... que... Qué poca vergüenza.

Trinker.- Sí, qué poca.

Hunger.- Qué desfachatez.

Trinker. - ¿Entonces, no vienes?

Hunger.- Podría ir, pero... ¿ ¿dónde es?

Silencio.

Trinker.- ¿Cuánto tiempo llevas en Alemania?

Hunger.- Dos años.

1 A nuestro dirigente le ha encantado la función. Está deseando que vayan a visitarlo a la sede del partido.... Esta noche. No falten. 
TRINKER.- ¿Y?

Hunger. - Y dos meses. Dos años y dos meses.

TRINKER.- Y nada....

Hunger.- Me aprendí las líneas que decimos en el número; para pedir en los bares pido con éste (muestra el dedo índice), pero del telegrama no he entendido ni una palabra.

Trinker.- Nos invitan a una función privada.

Hunger. - ¿Cuándo?

Trinker.- Esta noche.

Hunger.- - He quedado con la contorsionista polaca.

Trinker.- No querrán posponerla.

Hunger.- ¿Para quién es?

Trinker.- Para un político.

Hunger.- Prefiero enredarme con la contorsionista. (Pausa) ¿Pagan?

TRINKER.- Supongo.

Hunger. - ¿Cómo supones? ¡Mira en el telegrama!

Trinker.- Hay una dirección. Podría ser la oportunidad que estábamos esperando.

HUNGER. - ¿Y si se entera el director?

TRINKER.- No tiene porqué enterarse.

Hunger. - Igual deberías ir solo.

Trinker.- Antes no hablaba en serio.

Hunger.- No sé...

Trinker.- Está bien, nos quedamos en este agujero oliendo a mierda de elefante.

Hunger se sienta. Abre el periódico Völkischer Beobachter. ${ }^{2}$

Trinker.- Mira, aquí hablan de él.

Hunger. - ¿Del elefante?

Trinker.- No, del político.

Hunger.- ¿Qué dice?

Trinker. - Mmmmm... nada, tonterías nacionalistas, poder alemán, orgullo... Lo de siempre.

Aplausos. Voces ininteligibles del Jefe de pista. Hunger y Trinker se colocan detrás de la cortina de salida.

Hunger.- ¿Trae foto?

TRINKER.- Sí, sí...

Hunger.- No puede ser. Si este es un payaso buenísimo.

2 El Observador del Pueblo. 
Trinker.- Se parece.

Hunger. - ¿Cómo se parece? Son clavaditos, solo le falta el bombín. Me encanta.

Trinker. - ¿El político?

Hunger. - No, el payaso.

TRINKER.- Un poco vulgar.

Hunger. - ¿Vulgar? Venga ya.

Trinker.- - Le falta profundidad. Con los ingleses ya se sabe.

Hunger. - ¿Inglés?

TRINKER.- Sí.

Hunger.- No lo sabía. Ya me gusta menos, pero es buenísimo.

Trinker. - ¿Entonces, qué? ¿Vamos?

Aplausos.

Hunger.- Pero sin experimentos, le hacemos el número de las tartas y el bate de béisbol; y si quiere más: "La abejita”, y "Guillermo Tell”.

Suena el "Cascanueces". Unos últimos retoques antes de salir a la pista.

Hunger. - ¿De qué partido es?

Trinker.- Del Partido Nacional Socialista Obrero Alemán.

Hunger. - Ni idea. ¿Cómo se llama?

TRINKER.- ¿Quién?

Hunger.- El político.

Trinker.- Hitler, Adolf Hitler.

Hunger.- Espero que nos invite a un filete.

Trinker.- Lo dudo, creo que es vegetariano.

Hunger.- Bueno, un tipo que se parece a Chaplin no puede ser mala gente.

TRINKER.- ¿Te apuntas?

Hunger.- Claro, dos payasos judíos en la sede del partido nacionalsocialista junto a Adolf Hitler, ¿qué puede salir mal? Sonríe, esta noche nos cambiará la vida. Trinker.- ¡Ey, nuestro pie!

Salen a la pista vestidos de bailarina y director de orquesta... En la que quizás sea su última función. 